\section{Ontogeny of Crown Bud Clusters and Dormancy-breaking Treatments Influence Productivity and Spread of Harvest Maturity of Gentian 'Showtime Diva'}

\author{
Uttara C. Samarakoon ${ }^{1}$ and David J. Woolley \\ Institute of Agriculture and Environment, Massey University, Palmerston \\ North 4474, New Zealand
}

Ed R. Morgan

The New Zealand Institute for Plant \& Food Research Limited, Private Bag 11,600, Palmerston North 4442, New Zealand

Keith A. Funnell ${ }^{2}$

Institute of Agriculture and Environment, Massey University, Palmerston North 4474, New Zealand; and The New Zealand Institute for Plant \& Food Research Limited, Private Bag 11,600, Palmerston North 4442, New Zealand

Additional index words. Gentiana triflora $\times$ Gentiana scabra, herbaceous perennial, bud hierarchy, dormancy, cold, gibberellic acid, flowering

\begin{abstract}
Cut flower productivity and quality of gentian is associated with growth and development of crown buds. Experiments were carried out with the gentian cultivar Showtime Diva to identify the response to treatments that break dormancy [cold temperature (chilling), gibberellic acid $\left(\mathrm{GA}_{3}\right)$ ] applied at different stages of development of crown buds (plants with nonemerged crown buds, shoots recently emerged, or shoots emerged and elongated). The comparative growth potential of crown buds within the cluster was also investigated. At the stages of development examined, the application of $\mathrm{GA}_{3}(100 \mathrm{ppm})$ increased emergence of crown buds as shoots, leading to development of more flowering shoots. A similar response was observed with exposure to cold, but only on plants with nonemerged crown buds. Shoot emergence increased in response to increased duration of cold from 0 to 42 days $\left(5^{\circ} \mathrm{C}\right)$. Both chilling and $\mathrm{GA}_{3}$ could potentially be used to reduce the duration to, and spread of, harvest maturity if applied before shoot emergence. The hierarchical relationship of buds in crown bud clusters led to differential responses to application of $\mathrm{GA}_{3}$. Buds ontogenetically positioned at the proximal end of the bud cluster took a similar duration to reach shoot emergence or harvest maturity. For buds located at the distal end there was a positive correlation between ontogenetic bud position and the duration to reach shoot maturity. Shoot length and number of nodes at harvest maturity showed slight negative correlations with the position of the bud in the bud cluster. The results provide an explanation for possible sources of the variation in quality and quantity of floral shoots, and spread in time to harvest maturity within a single plant, and with development stage.
\end{abstract}

In recent years, new gentian cultivars (particularly Gentiana triflora Pall and Gentiana scabra Bunge) have been released for production of cut flowers or potted plants. As a herbaceous perennial, gentians overwinter as a crown comprised of an underground stem, various sized buds (crown buds), storage roots, and feeding roots (Ohkawa, 1983). Crown buds arise as separate units comprising several associated buds, with one such unit comprising two or more buds arranged in a spiral pattern along a compressed stem axis referred to as a bud cluster (Samarakoon et al., 2014). The hierarchical arrangement of the crown buds from the proximal to distal end of the cluster defines the ontogenetic timing of development of buds from the earliest to latest within the cluster and, therefore, their degree of maturity (Samarakoon et al., 2014). One of the crown buds within the cluster would be an apical bud capable of producing more buds during the growth cycle, and the other crown buds would be axillary and capable of developing into flowering shoots. Flowering shoots of gentian develop from the overwintering crown buds produced in the previous growing season. Crown buds are dormant in winter until growth recommences in spring when they emerge, with floral initiation evident once axillary shoots become visible in leaf axils of the developing flowering shoot (Samarakoon, 2012), and anthesis in later summer through early fall (Samarakoon et al., 2010, 2012). While greater shoot emergence leads to a greater number of shoots at harvest, not all crown buds present at the beginning of a growing season emerge as shoots leading to loss of yield (Samarakoon et al., 2012).

Shoot emergence, development, and flowering, only occur in some temperate perennials when requirements for prior exposure to cold temperature (chilling) have been satisfied, i.e., vernalization and/or breaking of endodormancy (Iversen and Weiler, 1994). Inadequate accumulation of chill units can result in delayed or uneven shoot emergence, reduced budbreak, and slow or weak shoot growth in a range of plant species (Lang et al., 1987), and while evidence exists that prior exposure to chilling is required for crown buds of gentian to emerge in spring (Samarakoon et al., 2012), peer-reviewed articles defining the specific timing and requirements for floral induction, initiation, and shoot development to flowering, are limited. In regions with mild winter temperatures, such as New Zealand (NZ), inadequate accumulation of chill units was hypothesized as a possible reason for variation in timing and quality of shoot emergence and flowering.

Exogenous application of $\mathrm{GA}_{3}$ is known to replace (Dahanayake and Galwey, 1999), or partially replace (Zieslin and Geller, 1983) chill unit requirements in a range of herbaceous perennials. In a summary of unpublished technical reports based on older cultivars of gentian, the application of $\mathrm{GA}_{3}$ $(100 \mathrm{ppm})$ resulted in shoot emergence in dormant plants, but these shoots did not produce flowers (Ohkawa, 1983). The role of $\mathrm{GA}_{3}$ in substitution of chilling with application to the current new cultivars remained to be investigated.

Because of the hierarchal arrangement of buds within clusters, paradormancy (correlative inhibition) is likely to exist within the cluster (Samarakoon et al., 2014) and, based on the comparative growth potential of individual buds, could lead to differences in response to dormancy-breaking treatments. This could also influence the time needed for a bud to reach horticulturally relevant developmental endpoints such as shoot emergence or flower harvest maturity and, therefore, spread in duration to harvest maturity of the flowering shoots within a single plant. Such spread in duration of harvest maturity has previously been identified as a concern by commercial growers (Samarakoon et al., 2013).

In commercial practice, dormancybreaking treatments would ideally be applied early in the growing season, potentially in winter or spring, before shoot emergence. In hybrid cultivars of gentian like Showtime Diva, at the beginning of the annual growth cycle in spring crown buds/shoots are likely to be at different stages of development, i.e., from nonemerged crown buds through to developing shoots (Samarakoon et al., 2014). With these stages of development in mind, in this paper we describe the effects of adequate and inadequate chilling and the use of $\mathrm{GA}_{3}$ as a substitute for chilling on shoot 
emergence and development for the cultivar Showtime Diva. The potential differential response to chilling and/or $\mathrm{GA}_{3}$ was investigated by applying these treatments to plants with buds and shoots at different stages of development. To develop an understanding of the developmental hierarchy within crown bud clusters, the correlations between timing of shoot emergence and flowering and the position of buds within the cluster was investigated.

\section{Materials and Methods}

General management of plants. Plants of the cultivar Showtime Diva were propagated by tissue culture at The New Zealand Institute for Plant \& Food Research (Palmerston North, NZ; 40 $\left.22^{\prime} \mathrm{S} 175^{\circ} 37^{\prime} \mathrm{E}\right)$. After a root plug had established, plants were potted into black polythene bags $(1.7 \mathrm{~L})$ using a growing medium that composed of A-grade bark $(50 \%)$, bark fiber $(30 \%)$, and $7-\mathrm{mm}$ pumice $(20 \%)$ supplemented with $1 \mathrm{~kg} \cdot \mathrm{m}^{-3}$ serpentine superphosphate, $1.5 \mathrm{~kg} \cdot \mathrm{m}^{-3}$ dolomite, $2 \mathrm{~kg} \cdot \mathrm{m}^{-3}$ 8- to 9-month Osmocote ${ }^{\circledR}$ (16N-3.5P-10K; Everris International, Geldermalsen, the Netherlands), and $1 \mathrm{~kg} \cdot \mathrm{m}^{-3} 3-$ to 4-month Osmocote ${ }^{\circledR}(15 \mathrm{~N}-4.8 \mathrm{P}-10.8 \mathrm{~K})$. Plants were grown in a greenhouse (heated at $15^{\circ} \mathrm{C}$, ventilated at $20^{\circ} \mathrm{C}$ ) to avoid accumulation of chill units, and under a long photoperiod with a 2 -h night-break lighting (4.6 $\mu \mathrm{mol} \cdot \mathrm{s}^{-1} \cdot \mathrm{m}^{-2}$ ) given daily at 23:00 $\mathrm{HR}$ so as to avoid a potential, confounding, photoperiodic response. Plants were irrigated using a drained capillary system, which supplied between 50 and $60 \mathrm{~mL}$ of water per plant per day, supplemented with one overhead watering per week, although during cold treatments, plants were only hand watered as required.

At the beginning of the second growth cycle, $\approx 8$ months after being deflasked, plants typically had one or two crown bud clusters and carried between one and three mature floral shoots (postanthesis), which had arisen and flowered during the first growth cycle. Plants were allocated into three categories for use in experiments based on

Received for publication 20 Jan. 2016. Accepted for publication 2 May 2016.

This work forms a portion of a thesis submitted by U.C. Samarakoon in fulfilling a $\mathrm{PhD}$ degree requirement. We thank the New Zealand Foundation for Research, Science and Technology (contract C02X0702), Plant \& Food Research Core funding: 1198 - "Fashionable Plants for the Ornamentals Industry," 1972- "Breeding Technology Development," George Mason Charitable Trust and Massey University Doctoral Scholarship for financial support. Technical assistance from James Slater and Kay Kitchen, support for statistical analysis from Duncan Hedderley, and manuscript review comments from John Seelye and Glenn Clark are greatly appreciated.

${ }^{1}$ Current address: The Ohio State University, 1328 Dover Road, Wooster, OH 44691

${ }^{2}$ Corresponding author. E-mail: keith.funnell@ plantandfood.co.nz. the degree of development of their crown buds and/or crown shoots at the beginning of the second growth cycle. These categories comprised plants with nonemerged buds, which had visible crown buds but no shoot emergence; recently emerged shoots, which in addition to the nonemerged visible crown buds had one to three recently emerged shoots (less than $2.5 \mathrm{~cm}$ long); elongated shoots, which in addition to nonemerged crown buds, had both recently emerged and elongated (up to $16 \pm 1 \mathrm{~cm}$ ) shoots. Both recently emerged and elongated shoots had not yet commenced floral initiation when the experiments commenced.

Treatment application. Cold treatments, i.e., chilling $\left(5^{\circ} \mathrm{C}\right)$ comprised placing plants in a cool store with a 16-h photoperiod and a light intensity of $4.9 \mu \mathrm{mol} \cdot \mathrm{s}^{-1} \cdot \mathrm{m}^{-2}$ at plant height provided by incandescent bulbs.

$\mathrm{GA}_{3}$ (OlChemIm Ltd., Olomouc, Czech Republic) was applied to the foliage, exposed crown, and surface of the growing medium, as a spray to runoff $(\approx 70 \mathrm{~mL}$ per plant $)$ at either $100 \mathrm{ppm}\left(+\mathrm{GA}_{3}\right)$ or $0 \mathrm{ppm}\left(-\mathrm{GA}_{3}\right.$; control). $\mathrm{GA}_{3}$ was prepared by dissolving in 95\% ethanol, and diluted to the required volume with distilled water together with $0.05 \%$ Tween $^{\circledR} 20$ (Sigma-Aldrich CAS No. 9005-64-5, St. Louis, MO) as a surfactant, and less than $0.05 \%$ ethanol in the final treatment solution. The control treatment $\left(-\mathrm{GA}_{3}\right)$ comprised water, ethanol, and Tween 20. To ensure foliar absorption was not limited by low temperatures, $\mathrm{GA}_{3}$ treatments were applied $3 \mathrm{~d}$ after plants were transferred from the cool store to the heated greenhouse.

Expt. 1: Plants with buds nonemerged. Cold treatments comprised $5^{\circ} \mathrm{C}$ for $0,2,7$, or $42 \mathrm{~d}$. For plants in the treatment with $0 \mathrm{~d}$ of cold exposure, $\mathrm{GA}_{3}$ was applied at either 100 ppm $\left(+\mathrm{GA}_{3}\right)$ or 0 ppm (-GA 3 ; control). Hence there were five treatments in total, with either five or six individual plant replicates per treatment.

Expt. 2: Plants with shoots recently emerged. Plants with recently emerged shoots (less than $2.5 \mathrm{~cm}$ ) at the start of their second growth cycle received one of six treatments of cold and/or $\mathrm{GA}_{3}$. Plants within three durations of cold exposure $(0,2$, or $42 \mathrm{~d})$ were treated with $\mathrm{GA}_{3}$ at $100 \mathrm{ppm}$ $\left(+\mathrm{GA}_{3}\right)$ or with no $\mathrm{GA}_{3}\left(-\mathrm{GA}_{3}\right.$; control). There were seven or eight individual plant replicates per treatment combination.

Expt. 3: Plants with shoots emerged and elongated. Plants with elongated shoots were treated with the same combinations of cold and/or $\mathrm{GA}_{3}$ described in Expt. 2. Due to nontreatment-related plant losses, the number of replicates ranged between nine and fourteen individual plants per treatment combination.

Expt. 4: $\mathrm{GA}_{3}$ and bud ontogeny within the cluster. Plants at a similar stage of development to that in Expt. 1 were selected, but at the end of their second growth cycle. Plants had one or two crown bud clusters (three to seven nonemerged crown buds per cluster) and two to three mature floral shoots (postanthesis).
There were two treatments with four individual plant replicates per treatment. $\mathrm{GA}_{3}$ ( 0 or $100 \mathrm{ppm}$ ) was applied onto the foliage of existing mature floral shoots. Three days later, the shoots were all excised at their bases (leaving no nodes) and the same $\mathrm{GA}_{3}$ treatments ( 0 or $100 \mathrm{ppm})$ reapplied to the exposed crown and the surface of the growing medium.

Variables recorded or calculated. A crown bud was defined as having emerged as a crown shoot when it was more than $2.5 \mathrm{~cm}$ in height. These crown shoots were considered to have reached commercial maturity when the uppermost flower bud had developed color but had not yet opened (Eason et al., 2004). So as to accommodate any influence of variable number of crown buds between individual replicates, in all experiments the number of visible, nonemerged crown buds was recorded before applying treatments. At flower harvest maturity for crown shoots (i.e., other than floral shoots of the first growth cycle), the duration from treatment to flower harvest maturity, shoot length, number of nodes, and the number of floral axillaries on crown shoots were recorded. So as to accommodate any influence of variable number of crown shoots between individual replicates, within Expts. 2 and 3 additional data recorded before application of treatments included the number of crown shoots emerged but not developed, the number of crown shoots which had emerged and elongated, and their shoot length.

Within Expt. 4, growth and development of crown buds and shoots within clusters were tracked as detailed previously (Samarakoon et al., 2010, 2012). Data were collected before applying treatments, then at weekly intervals for the first 7 weeks following the last treatment, and thereafter at 6-week intervals until two growth cycles had been completed (24month duration). Data collected before treatment application included the hierarchical position of individual crown buds within a cluster, and the position of the previous season's senesced shoots. Throughout the period of data collection, the order of appearance of crown buds and of shoots within a cluster was tracked for individual bud clusters. To identify the hierarchical position of crown buds and shoots within a cluster, each bud was numbered in ascending order from the proximal end of the cluster toward the distal end, i.e., from the ontogenetically oldest to the most recently developed, youngest bud. This continued as new crown buds became visible next to the bud previously noted as being most recent. The dates of shoot emergence and harvest maturity of these numbered crown buds were tracked and recorded.

For Expts. 1 and 4, the number of crown shoots that emerged and reached harvest maturity was calculated as a proportion of the number of visible crown buds present at the time of treatment application. This proportion sometimes exceeded $100 \%$ as new crown buds became visible and developed 
into shoots during the course of the experiment. For Expts. 2 and 3, the number of crown shoots that reached harvest maturity was calculated as a proportion of the combined number of visible crown buds and crown shoots, either emerged or developed, within a plant at the time of treatment.

Experimental design and statistical analysis. All experiments were arranged as a completely randomized design. Data were analyzed using the general linear models procedure in Statistical Analysis Software (SAS) (version 9.2; SAS Institute, Cary, NC). If data were not normally distributed, either a square root or log transformation was carried out. Means were separated using either Duncan's new multiple range test or the Scheffe test, depending on the number of replicates available.

In Expt. 3, the variables recorded at harvest, relative to crown shoots already present at the time of treatment, were analyzed using the covariance procedure in SAS, i.e., for each individual shoot. Shoot length at the time of treatment was considered as a covariate for the variables duration to harvest maturity and shoot length at harvest. The number of nodes at time of treatment was used as a covariate for analyzing the number of nodes at harvest, and the number of nodes with floral axillaries at harvest. Means were separated using LSMEANS at the $0.05 \%$ level, but the means presented are weighted means.

Box and whisker plots (Sigma Plot version 10; Systat Software Inc., San Jose, CA) were used to describe quantitatively the distribution of duration from the date the last treatment was applied through to harvest maturity (Samarakoon et al., 2013). These data used those derived from the multiple shoots across all replicates collectively. The $80 \%$ spread was calculated based on the number of days to harvest maturity between the 10th and 90th percentiles of the box and whisker plot. Within Expt. 3, 80\% spread was also assessed separately for shoots that were present at the time of treatment application. Within Expt. 4, relationships between the position of the crown bud and the variables related to the duration to reach any developmental stage, or the quality variables of shoots, were evaluated using regression analysis (Sigma Plot version 10; Systat Software Inc.). Correlations were determined using all the crown shoots which emerged within all individual plant replicates.

\section{Results}

Expt. 1: Plants with buds nonemerged. When expressed as a proportion of the crown buds present at treatment application, there was an increase in shoot emergence in response to chilling, as evident from the 2- to 8 -fold increase in shoot emergence with the increased duration of cold from 2 to $42 \mathrm{~d}(P<$ 0.05 ; Fig. 1A). All shoots which emerged ended up flowering irrespective of treatment and, therefore, treatments with increased shoot emergence led to a greater number of
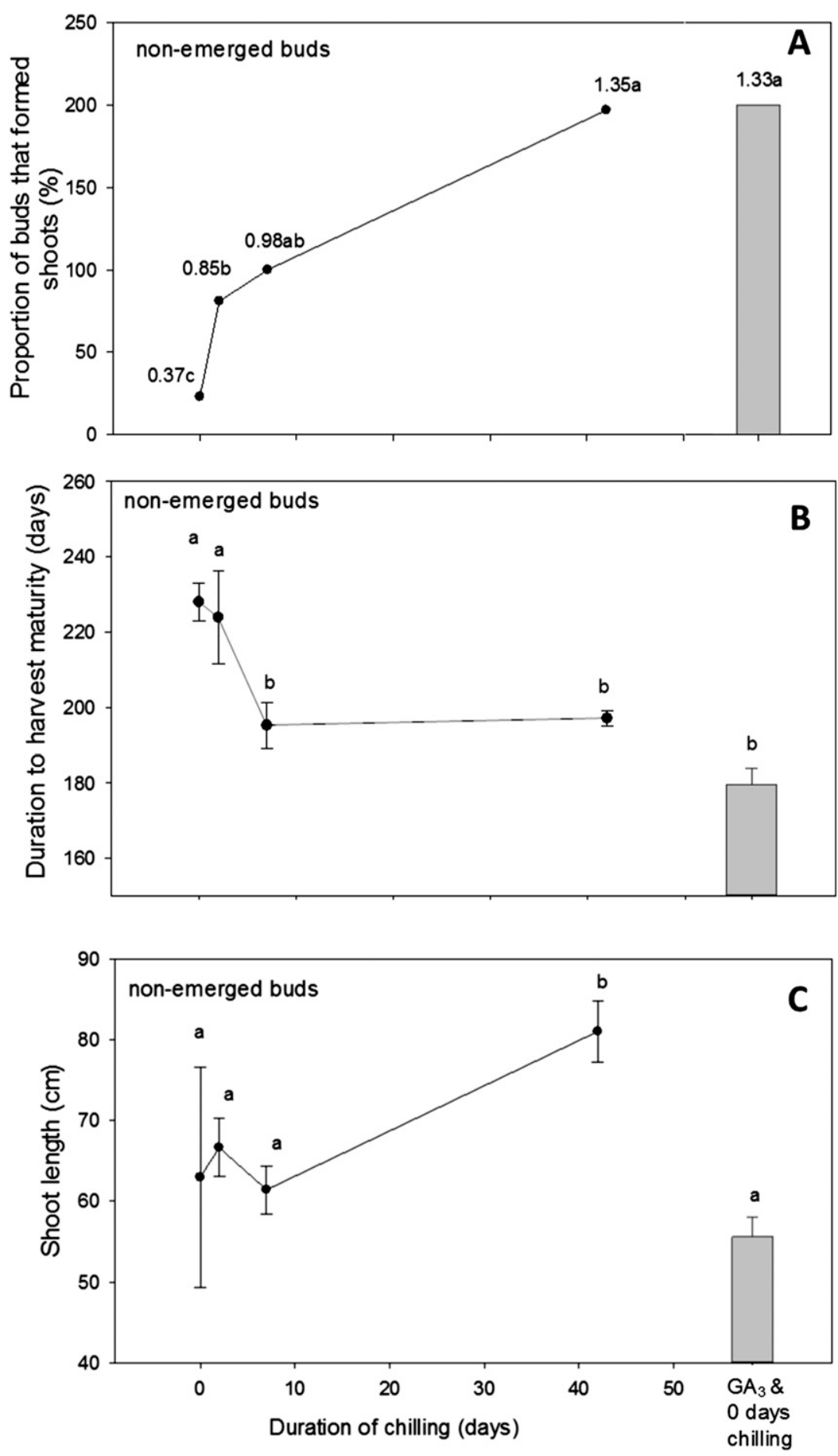

Fig. 1. (A) Proportion of 'Showtime Diva' gentian shoots emerged and reaching harvest maturity compared with nonemerged crown buds present at the time of first treatment application, (B) duration to harvest maturity for each shoot, and (C) shoot length at harvest, following increasing duration of cold at $5{ }^{\circ} \mathrm{C}$ or application of gibberellic acid to plants with nonemerged buds (Expt. 1). For each variable, means with different letters were significantly different. Within (A), mean separation is based on the log-transformed means (value presented in figure along with mean separation letter). Vertical lines represent $\pm \mathrm{SE}$. Mean separation by Duncan's new multiple range test at $P<0.05, \mathrm{n}=5$ or 6 .

floral shoots at harvest. $\mathrm{GA}_{3}$ at $100 \mathrm{mg} / \mathrm{L}$ stimulated shoot emergence to a degree similar to that achieved by $42 \mathrm{~d}$ of cold (Fig. 1A). As a result, the number of floral shoots per plant was greater $(P<0.05)$ following application of $\mathrm{GA}_{3}(5 \pm 1)$ than in treatments with either $0 \mathrm{~d}(1 \pm 0)$ or $2 \mathrm{~d}$ of cold $(2 \pm 0)$. While the level of statistical significance was only
$P=0.1$, the number of floral shoots harvested following $42 \mathrm{~d}$ of cold was three times greater than that achieved with $0 \mathrm{~d}$ of cold (i.e., from one to three shoots).

Application of either cold or $\mathrm{GA}_{3}$ to plants with nonemerged crown buds reduced the duration to harvest maturity $(P<0.0001)$, with plants receiving either 7 or $42 \mathrm{~d}$ of cold, 
or $\mathrm{GA}_{3}$, reaching harvest between 28 and $49 \mathrm{~d}$ earlier than treatments with 0 or $2 \mathrm{~d}$ of cold (Fig. 1B). The $80 \%$ spread in timing of flower harvest maturity was reduced with application of "sufficient" chilling and with application of $\mathrm{GA}_{3}$ (Fig. 2A). Even with the greater number of shoots produced following $42 \mathrm{~d}$ of cold, the $80 \%$ spread in timing of flower harvest maturity was 83 and $20 \mathrm{~d}$ less than observed following either $2 \mathrm{~d}$ of cold or $\mathrm{GA}_{3}$, respectively. (The treatment with no chilling and no $\mathrm{GA}_{3}$ achieved a spread of $15 \mathrm{~d}$; however, there were only three shoots for all the replicates in this treatment.)

At harvest maturity, shoots arising following $42 \mathrm{~d}$ of cold were $\approx 20 \mathrm{~cm}$ longer than those in all other treatments $(P<0.0001$; Fig. 1C). The total number of nodes at harvest did not vary significantly among treatments, however $(P>0.05)$.

Expt. 2: Plants with shoots recently emerged. As noted within Expt. 1, all shoots emerged, flowered irrespective of treatment and, therefore, treatments with increased shoot emergence led to a greater number of floral shoots at harvest. When expressed as a proportion of the combined total of crown buds and crown shoots present at treatment application, the proportion of shoots that reached harvest maturity increased when plants were treated with $\mathrm{GA}_{3}(P<0.0001$; Fig. 3A). This was evident in treatments receiving $\mathrm{GA}_{3}$ after either 0 or $2 \mathrm{~d}$ of cold exposure, achieving between two and three times more shoots than in all other treatments. In contrast to Expt. 1, exposure to cold at this stage of development did not increase rates of shoot emergence. Even with application of $\mathrm{GA}_{3}$, exposure to $42 \mathrm{~d}$ of cold halved the rate of shoot emergence compared with that of plants receiving no or limited chilling (Fig. 3A). As evident from values of shoot emergence greater than $100 \%$ in treatments with $\mathrm{GA}_{3}$, crown buds, which were not visible at the commencement of the experiment, emerged as shoots.

Treatment differences for the number of floral shoots harvested followed a similar trend of treatment effects to that of the proportion of buds and shoots that reached harvest maturity $(P<0.0001)$. Application of $\mathrm{GA}_{3}$ after 0 or $2 \mathrm{~d}$ of cold produced between two and four more floral shoots per plant than the treatment with $42 \mathrm{~d}$ of cold and the treatments that received no $\mathrm{GA}_{3}$.

Shoot length at harvest was primarily influenced by the duration of cold, with plants receiving $42 \mathrm{~d}$ of cold and the control treatment producing shoots that were between 16 and $26 \mathrm{~cm}$ longer than those from other treatments $(P<0.01$; Fig. 3B). Application of $\mathrm{GA}_{3}$, however, resulted in reduced shoot lengths at harvest, with plants receiving $42 \mathrm{~d}$ of cold-producing shoots on average $16 \mathrm{~cm}$ shorter $(P<0.01)$. No treatment effect was evident on the number of nodes on shoots at harvest $(P>0.05$; data not shown). By contrast, plants receiving $42 \mathrm{~d}$ of cold and no $\mathrm{GA}_{3}$ produced five to eight more nodes with floral axillaries than plants in all other treatments $(P<0.0001)$. The duration to harvest
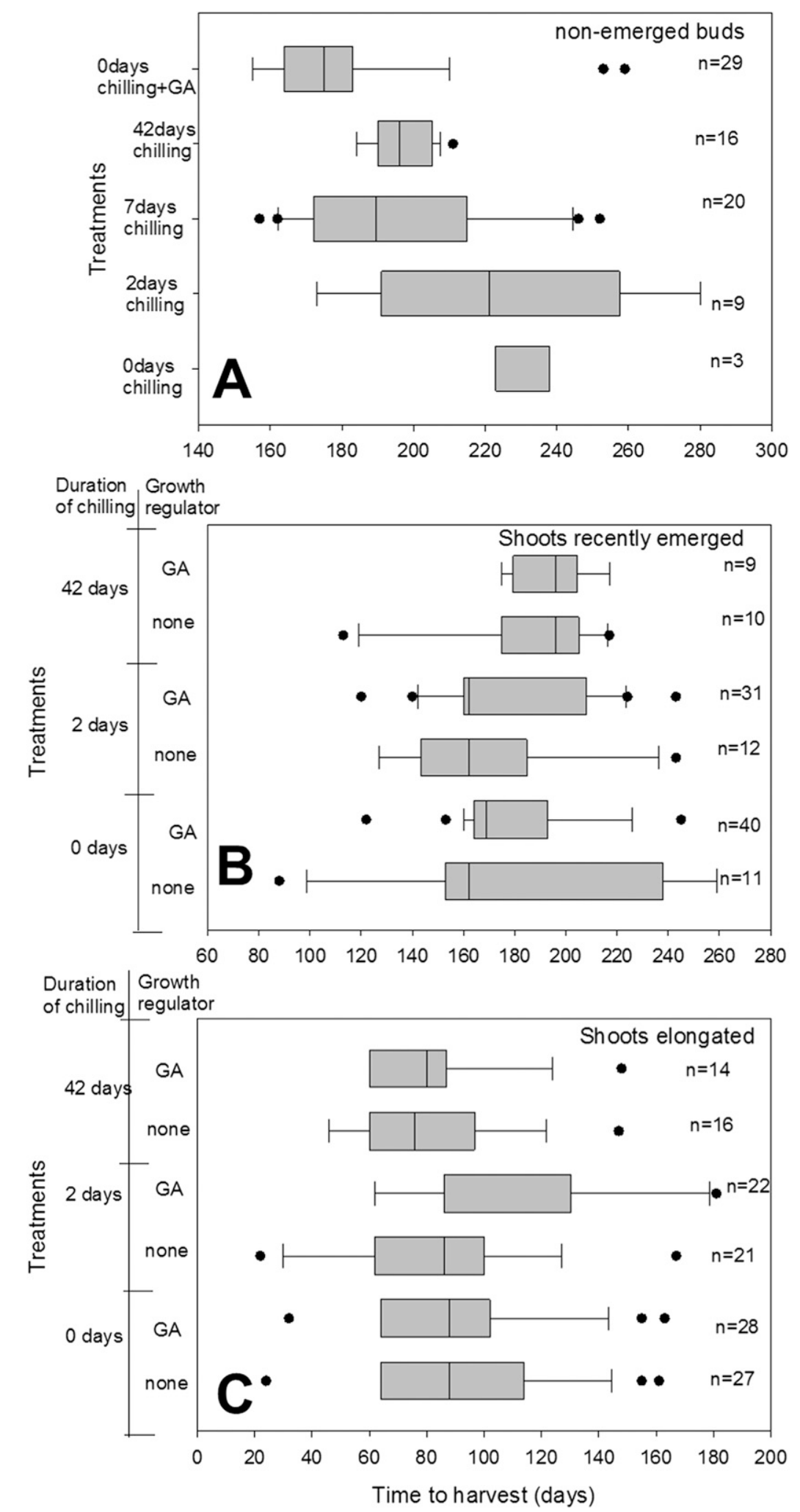

Fig. 2. Spread in time to harvest maturity of shoots following treatment application to plants of 'Showtime Diva' gentian at three developmental stages, comprising (A) nonemerged buds (Expt. 1), (B) shoots recently emerged (Expt. 2), (C) shoots emerged and elongated (Expt. 3). The number of shoots contributing to the distribution is indicated to the right of each treatment's box plot. Solid lines in the center of each box indicate the median. Boundaries of the box indicate the 25th and 75th percentiles, whiskers indicate 10th and 90th percentiles and, solid dots indicate one or more individuals as outliers beyond these percentile limits. $\mathrm{GA}_{3}=$ gibberellic acid.

was unaffected when cold or $\mathrm{GA}_{3}$ was applied to plants with shoots recently emerged $(P>0.05)$, with an average for all treatments of $177 \pm 10 \mathrm{~d}$.
Poor plant survival following $42 \mathrm{~d}$ of cold resulted in significant variation in the data for the $80 \%$ spread in time to harvest maturity. Compared with time in the no-chilling 

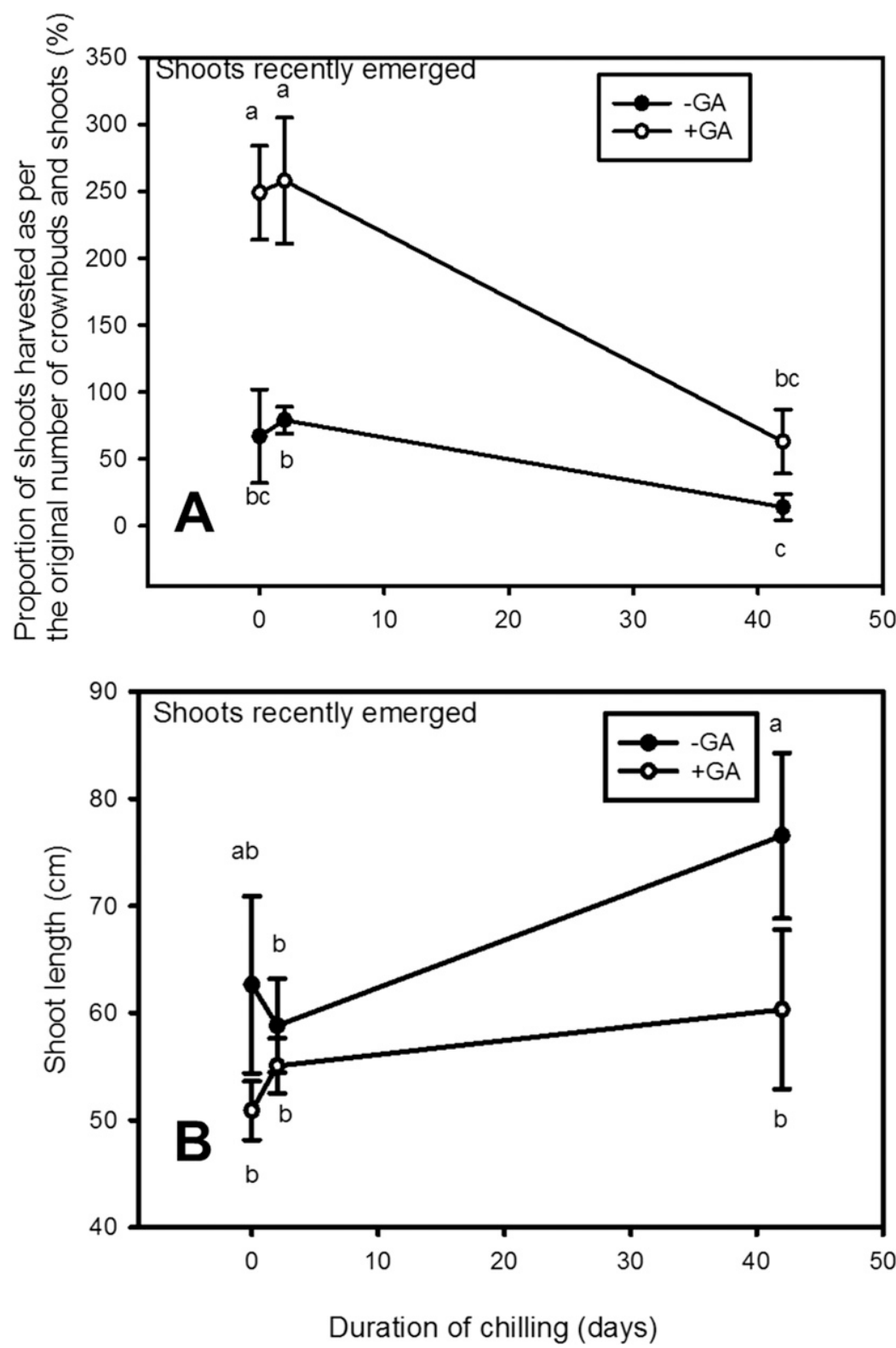

Fig. 3. (A) Proportion of 'Showtime Diva' gentian shoots reaching harvest maturity compared with the combined number of nonemerged crown buds and crown shoots visible at the time of first treatment application and (B) shoot length at harvest of shoots developed following increasing duration of cold at $5{ }^{\circ} \mathrm{C}$ and/or application of gibberellic acid $\left(\mathrm{GA}_{3}\right)$ to plants with shoots recently emerged (Expt. 2). For each variable, means indicated by different letters were significantly different. Vertical lines represent \pm SE. Mean separation by Duncan's new multiple range test at $P<0.05, \mathrm{n}=7$ or 8 .

treatment, the $80 \%$ spread in time to harvest maturity of shoots was reduced by 43 and $55 \mathrm{~d}$, respectively, following 2 and $42 \mathrm{~d}$ of cold (Fig. 2B). Application of $\mathrm{GA}_{3}$ reduced the $80 \%$ spread, irrespective of exposure to chilling. In treatments receiving no chilling, the $80 \%$ spread was reduced by half following application of $\mathrm{GA}_{3}$. Hence, this reduction of spread was observed (Fig. 2B) despite the increased shoot number $(7 \pm 1$ per plant; Fig. 3A). At the end of the second growth cycle, all plants that received 0 or $2 \mathrm{~d}$ of exposure to cold, both with and without application of $\mathrm{GA}_{3}$, survived. By contrast, $42 \mathrm{~d}$ of cold resulted in only $25 \%$ plant survival, which was increased to $50 \%$ when $\mathrm{GA}_{3}$ was applied.
$(P<0.0001)$, with application of $\mathrm{GA}_{3}$ with either $0(5 \pm 1)$ or $2 \mathrm{~d}(4 \pm 1)$ of cold achieving the greatest number of shoots. Of the shoots that were already elongated at the commencement of the experiment, the duration to harvest maturity was not influenced by chilling, or by $\mathrm{GA}_{3}(P>0.05)$, averaging $81 \pm$ $5 \mathrm{~d}$ (covariate-adjusted mean). The covariate, i.e., the initial height of the shoot at the commencement of treatment application, was significant for determining the duration to harvest maturity $(P<0.001)$. The same covariate was also significant for determining the length of the harvested shoot $(P<$ $0.0001)$. The covariate-adjusted shoot length was increased by $\mathrm{GA}_{3}$, with plants treated with $\mathrm{GA}_{3}$ following $42 \mathrm{~d}$ of cold producing the longest shoots, being $\approx 20 \mathrm{~cm}$ longer than those harvested from non- $\mathrm{GA}_{3}$-treated plants $(P<0.05$; Fig. 4B). There was no evidence of an influence of chilling or of $\mathrm{GA}_{3}(P>0.05)$ on the covariate-adjusted number of nodes $(10 \pm 2$; adjusted mean) or the number of nodes with floral axillaries $(5 \pm 1$; adjusted mean). The covariate number of nodes at the commencement of treatment application was significant for these two parameters $(P<$ 0.0001 and $P<0.001$, respectively).

The $80 \%$ spread in duration to flower harvest maturity was not consistent across all treatments (Fig. 2C). The narrowest $80 \%$ spread, which was $17 \mathrm{~d}$ less than that following $0 \mathrm{~d}$ of cold (control treatment), was observed in plants which received $42 \mathrm{~d}$ of cold. Although the spread was narrow, the number of shoots was also less (14 shoots) in plants receiving $42 \mathrm{~d}$ of cold than in the rest of the treatments.

For all floral shoots together, i.e., irrespective of whether elongated at the commencement of the experiment or not, the duration to harvest maturity $(89 \pm 7 \mathrm{~d})$ and number of nodes $(10 \pm 1)$ were not influenced by treatments $(P>0.05)$. Greater shoot lengths were observed in plants treated with $\mathrm{GA}_{3}$, irrespective of whether chilling was applied $(P<0.01)$. Application of $\mathrm{GA}_{3}$ with $2 \mathrm{~d}(54.5 \pm 4.4 \mathrm{~cm})$ or $42 \mathrm{~d}$ of cold $(54.5 \pm$ $5.8 \mathrm{~cm}$ ) resulted in longer shoots than those in plants receiving no chilling $(41 \pm 2.6 \mathrm{~cm})$. Exposure to chilling did not influence the shoot length, with plants receiving $2(41 \pm$ $3.6 \mathrm{~cm})$ or $42 \mathrm{~d}$ of cold $-(35 \pm 3 \mathrm{~cm})$ producing shoots with a similar length to those of plants receiving no chilling. When treatments were applied to plants with elongated shoots, the survival rates of plants were not greatly influenced by the treatments, ranging between $70 \%$ and $85 \%$.

Expt. 4: $\mathrm{GA}_{3}$ and bud ontogeny within the cluster-Morphological and developmental changes of a crown bud cluster. New crown buds appeared after the active growth of floral shoots, with most of these new buds originating through reactivation of the existing apical bud in the cluster. During the course of two growth cycles, the apical bud of a bud cluster never emerged as a floral shoot. The apical meristem of the cluster remained vegetative, while axillary buds developed as floral shoots and, therefore, the 

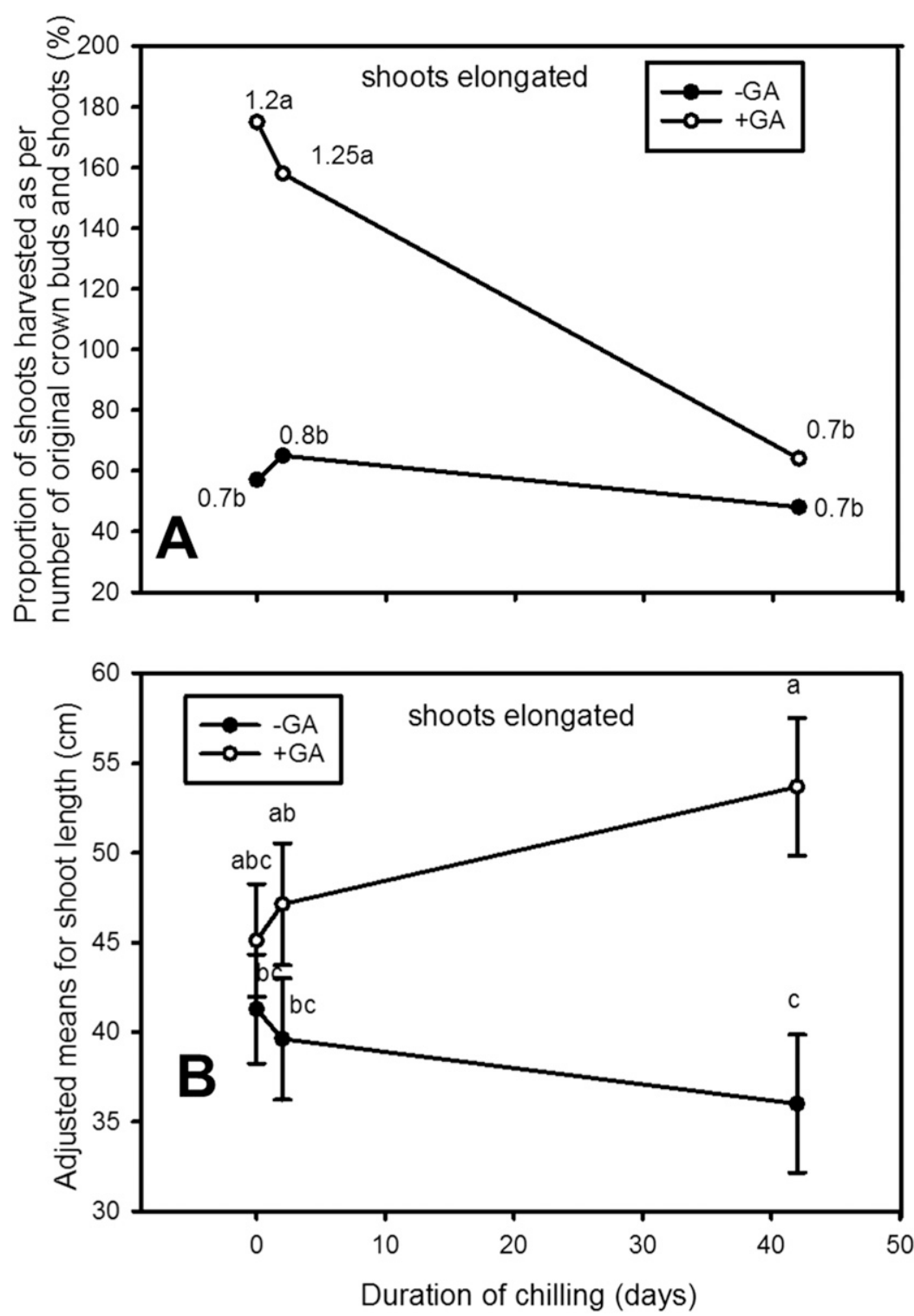

Fig. 4. (A) Proportion of 'Showtime Diva' gentian shoots reaching harvest maturity compared with combined number of nonemerged crown buds and crown shoots present at the time of first treatment application and (B) shoot length at harvest of shoots (present at the beginning of the treatment application; adjusted means are presented) following increasing duration of cold at $5{ }^{\circ} \mathrm{C}$ and/or application of gibberellic acid $\left(\mathrm{GA}_{3}\right)$ to plants with shoots emerged and elongated (Expt. 3). Within (A), mean separation is based on the log-transformed means. For each variable, log-transformed means indicated by different letters were significantly different. Vertical lines represent \pm SE. Mean separation by Duncan's new multiple range test at $P<0.05, \mathrm{n}=9-14$.

apical bud can be defined as having an indeterminate growth pattern. Only two plants within the experimental population were observed to develop new crown bud clusters from different points of attachment on the transition zone and, therefore, most of the floral shoots originated from existing crown bud clusters present at the time of plant establishment.

Shoot emergence and development. Application of $\mathrm{GA}_{3}$ induced shoot emergence from the crown buds that were not yet visible within the cluster, i.e., buds that had not yet been released from the most apical crown bud. When expressed as a proportion of the crown buds present at the commencement of treatment application, there was an $86 \%$ increase in shoot emergence with application of $\mathrm{GA}_{3}(108 \pm 8 \%)$ compared with that in the control $(22 \pm 8 \% ; P<0.0001)$. The spread in time to harvest maturity was $23 \mathrm{~d}$ greater in the control treatment than following application of $\mathrm{GA}_{3}$. Even with four times as many shoots, $50 \%$ of the shoots were harvested within $160 \mathrm{~d}$ of the last treatment application in the $\mathrm{GA}_{3}$ treatment, and this median date was $23 \mathrm{~d}$ earlier than for the control treatment (data not shown). With respect to those shoots within the $80 \%$ spread of time of harvest, $65 \%$ were harvested within $18 \mathrm{~d}$ when $\mathrm{GA}_{3}$ was applied, with no outliers evident. Of the late flowering shoots, $15 \%$ extended the harvest period by $10 \mathrm{~d}$, i.e., from 168 to $178 \mathrm{~d}$.
Influence of hierarchical position of the bud. In plants treated with $\mathrm{GA}_{3}$, the relationship between the numerical value of the hierarchical position of the crown buds and the duration to shoot emergence was positive, but depended on the hierarchical position of a bud. The older crown buds located at the proximal end, up to position 3 , had a similar duration to emergence, of $10 \pm 1 \mathrm{~d}$ (Fig. 5A). In contrast, crown buds that were younger and located at the distal end within the cluster (i.e., from position 4 and greater) were progressively longer in their duration to emergence, with an additional $14 \mathrm{~d}$ in duration required per unit increment in hierarchical position. No relationship between the hierarchical position and duration to emergence was evident within plants in the control treatment, which averaged $38 \pm 3 \mathrm{~d}$ (bud positions 2-6; data not shown).

Within the $\mathrm{GA}_{3}$ treatment, crown buds located at the proximal end, i.e., positions $1-3$, presented a similar duration to flower harvest maturity, with an average of $157 \pm 1 \mathrm{~d}$ (Fig. 5B). For buds closer to the distal end (from position 4 and greater) however, duration to harvest increased by $10 \mathrm{~d}$ with each unit increment in hierarchical position. Within the $\mathrm{GA}_{3}$ treatment, the duration between the two stages of emergence and harvest, displayed a similar pattern to that observed between the hierarchical position and duration to harvest $\left(R^{2}=0.51 ; P<0.001\right)$. No relationship between the hierarchical position and duration to harvest maturity was evident within plants in the control treatment, which averaged $186 \pm 14 \mathrm{~d}$ (bud positions 2-6; data not shown).

In the plants treated with $\mathrm{GA}_{3}$, negative correlations were evident between the quality variables of both shoot length (Fig. 5C) and number of vegetative nodes (Fig. 5D), and the hierarchical position of the buds from the proximal to distal end $(P<0.01)$. Buds at positions 1 and 2, however, had similar shoot lengths, of $71 \pm 3 \mathrm{~cm}$. The remaining buds, from positions 3 to 6 (i.e., the maximum position evaluated), displayed a $7-\mathrm{cm}$ decrease in shoot length per unit increment in hierarchical position. The total number of nodes on the shoots (vegetative and floral together) decreased by 1 to 2 nodes with each unit increment in hierarchical position. As noted with shoots from plants treated with $\mathrm{GA}_{3}$, the correlation between the number of vegetative nodes per shoot and the hierarchical position of the bud was negative, with a reduction of 2 nodes with each increment in hierarchical position $\left(R^{2}=0.61 ; P<0.05\right.$; Fig. $\left.5 \mathrm{D}\right)$. There was no correlation, however, between the number of axillary nodes which were floral and the hierarchical position of the bud $\left(R^{2}=0.13 ; P<0.05\right)$. For plants within the control treatment, while positive correlations with the hierarchical position of the bud for the total number of nodes was evident, the reduced number of stems in this treatment meant this was not significant $\left(R^{2}=0.75 ; P>0.05\right)$, and did not warrant further analysis. 

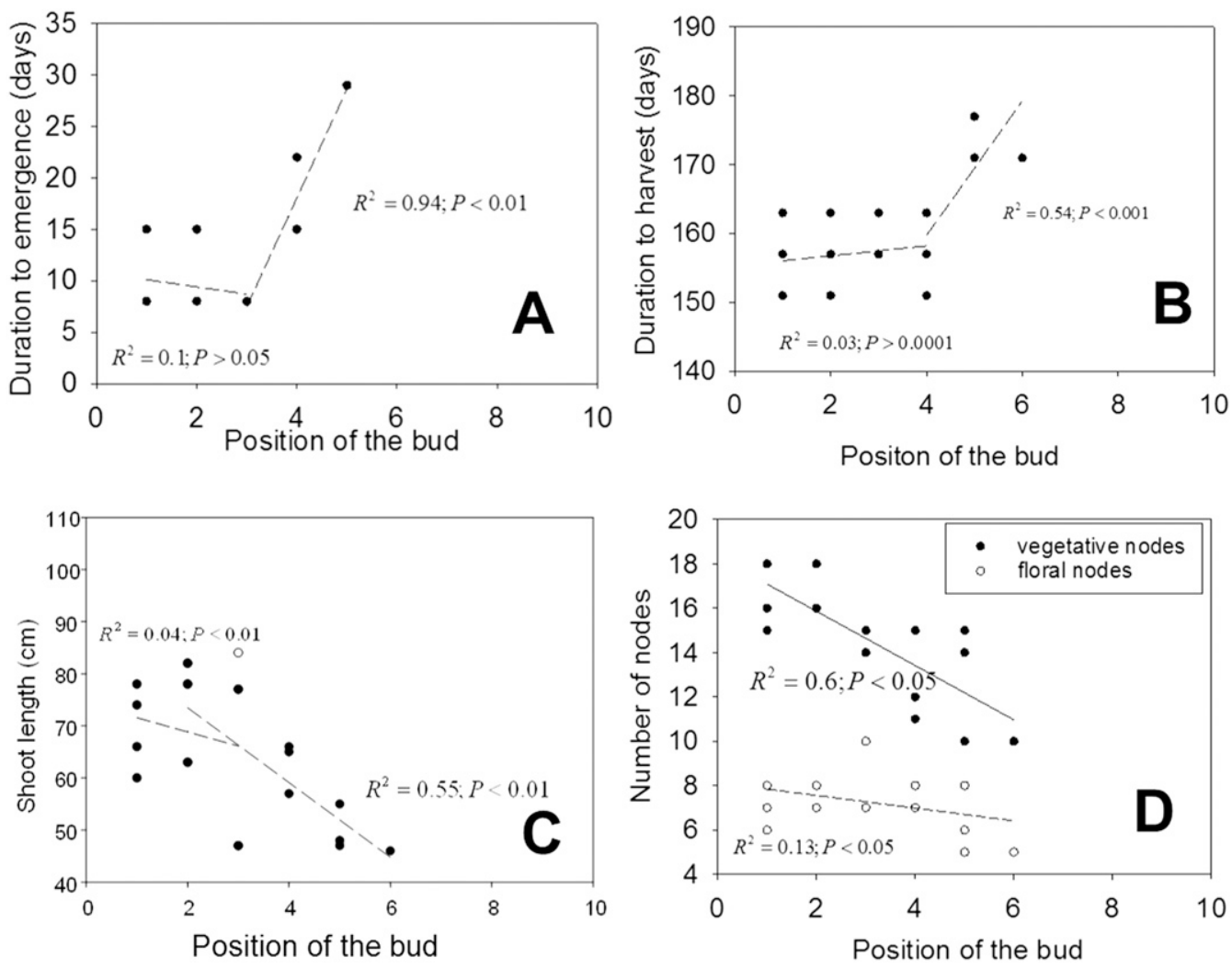

Fig. 5. Relationship between the hierarchical position of the 'Showtime Diva' gentian bud within the cluster, from proximal to distal end of the cluster and (A) duration to emergence, $(\mathbf{B})$ duration to harvest maturity, (C) shoot length, and (D) number of vegetative and floral nodes at harvest among $\mathrm{GA}_{3}$-treated plants in the first growth cycle following treatment application. Each data point represents one or more single shoots, $\mathrm{n}=16$.

\section{Discussion}

Shoot emergence. A change in response to chilling was observed and was dependent on the developmental stage of plants, with increased response to chilling observed when this was applied before shoot emergence, compared with later developmental stages (Figs. 1-4). The increased response to chilling when applied to crown buds before emergence (Fig. 1A) is interpreted as the crown buds being endodormant at this stage of development (Lang et al., 1987). As an increased duration of cold applied before emergence incrementally enhanced the proportion of shoots emerging (Fig. 1A), the chilling requirement in 'Showtime Diva' was consistent with it being a facultative response. From a horticultural perspective, promoting shoot emergence by ensuring adequate chilling enabled up to an 8 -fold greater numbers of floral shoots to be harvested.

Application of $\mathrm{GA}_{3}$ promoted shoot emergence at all the developmental stages examined. $\mathrm{GA}_{3}$ substituted for chilling in breaking endodormancy if applied before shoot emergence, as shown by the percentages of shoot emergence (approaching 200\%) and was similar to the treatment with the longest duration of cold (Fig. 1A). As evident in other plant species (Chao et al., 2007), it could be hypothesized that the stimulation of crown buds to emerge by chilling is associated with an increase in endogenous $\mathrm{GA}_{3}$.
Even if adequate chilling were not received, a single application of $\mathrm{GA}_{3}$ at $100 \mathrm{ppm}$ was sufficient to substitute for the chilling requirement to break endodormancy when applied before emergence in 'Showtime Diva'. Within a bud cluster, application of $\mathrm{GA}_{3}$ resulted in all crown buds that were visible, as well as some crown buds that were not yet visible within the cluster, as evidenced by shoot emergence at more than $100 \%$ (Fig. 1A). These previously nonvisible crown buds, which emerged as floral shoots within the same growth cycle as their appearance, were derived from the most apical bud of the existing bud clusters, which remained vegetative.

At the developmental stage before the start of emergence, $\mathrm{GA}_{3}$ substituted for the chilling requirement (to break endodormancy) for shoot emergence, but not when emergence had started, because plants were no longer endodormant. It could be hypothesized that once shoot emergence had started, $\mathrm{GA}_{3}$ stimulated emergence of crown buds which were under paradormancy (correlative inhibition) from already developing shoots and, presumably, from other buds within the cluster. Breaking of paradormancy of axillary buds of floral shoots, when $\mathrm{GA}_{3}$ was applied to plants without any crown buds, has previously been noted with 'Showtime Diva' (Samarakoon et al., 2015). In addition to endodormancy, $\mathrm{GA}_{3}$ therefore, can also break paradormancy of buds in 'Showtime
Diva', as also noted in other species (Chao et al., 2007).

Shoot development and time to flower harvest. The response to chilling and/or $\mathrm{GA}_{3}$ by shoot development and by flower harvest, varied based on the developmental stage of the plant at the time of treatment application (Figs. 1B and C, 3B, 4B), and the hierarchical position of crown buds within the cluster from which the shoots arose When applied before shoot emergence, exposure to cold reduced the duration to harvest maturity (Fig. 1B), as also noted in another herbaceous perennial, Helleborus (Christiaens et al., 2012). As flowering occurred in the absence of chilling, there is no obligate vernalization or endodormancy requirement in 'Showtime Diva', which contrasts with reports for other gentian cultivars (Ohkawa, 1983). Along with a greater number of shoots and early harvest maturity, shoot length was also greater with exposure to chilling before shoot emergence (Fig. 1A), as also reported in brassica species (Dahanayake and Galwey, 1999). When chilling was applied after shoot emergence, however, the shoot emergence and duration to harvest were unaffected, but shoot length and the number of nodes at harvest were increased (Figs. 3 and 4). Hence, it can be hypothesized that separate mechanisms control the effects of chilling on shoot emergence as compared with the multiple physiological events contributing to shoot development after emergence. 
When applied before emergence, $\mathrm{GA}_{3}$ increased shoot emergence and reduced the duration to harvest maturity, but was not capable of substituting for the effect of chilling on increased shoot length (Fig. 1C), as found in some species (Dahanayake and Galwey, 1999; Wanjao and Waithaka, 1983). As shoot elongation may be induced by chilling without involvement of endogenous $\mathrm{GA}_{3}$ (Ogasawara et al., 2001), the mechanism underlying the differential response observed here warrants future research.

Buds in the cluster that had developed earlier (occupying proximal positions) had similar durations to shoot emergence or harvest maturity, and were faster to reach these developmental points than buds developed later (distal positions; Fig. 5). This result is in accordance with correlations observed between the duration to emergence and harvest maturity in three gentian cultivars, including Showtime Diva (Samarakoon et al., 2013). In addition to the duration to reach a stage of development, qualitative characteristics of shoots (shoot length and number of nodes) also progressively increased with the position of the bud from the proximal to the distal end of the cluster. Thus, based on their hierarchical position, there was a differential response to dormancy-breaking treatments between the crown buds within the cluster. In rose (Marcelis-Van Acker, 1994), this differential response was a reflection of the degree of development of a bud. Alternatively, since endodormancy was broken by these treatments, later emergence of buds at the distal end could also be due to paradormancy within the cluster. The hierarchical position of the bud within the cluster therefore influences the duration to achieve a particular developmental endpoint, e.g., duration to harvest maturity, once endodormancy is broken. Thus the developmental potential of a crown bud is determined by its hierarchical position within the cluster, and the stage of development in the growth cycle.

Spread in flower harvest. Identifying strategies to reduce the spread in shoot emergence has previously been considered to be important to reduce spread in harvest maturity in 'Showtime Diva' (Samarakoon et al., 2013). Cultivation in a warm temperate climate could cause problems in cultivars with both obligate (low or delayed shoot emergence) and facultative (wide spread in flowering) requirements for chilling, because of the potential exposure to an inadequate number of chill units. Although shoot emergence could be early in a cultivar with a facultative chilling requirement (e.g., 'Showtime Diva'), increased rates of shoot emergence (Fig. 1A) reduced duration to harvest maturity (Fig. 1B), and a narrower spread of time to harvest maturity was achieved when plants received the longest duration of chilling before emergence (Fig. 2). With a facultative requirement of chilling for shoot emergence, ensuring adequate chilling before emergence is likely to be a key strategy in reducing the spread in time to harvest maturity. In a situation where chill units are inadequate, however, $\mathrm{GA}_{3}$ could substitute for the requirement to achieve a similar effect on spread in time to harvest maturity as is normally achieved with complete satisfaction of the chilling requirement (Fig. 2).

Variation in duration to harvest maturity was observed between individual crown buds within a bud cluster, thereby contributing to a spread in flower harvest maturity. With those shoots taking longer to reach harvest originating from crown buds at Position 4 or later, it is considered plausible that these shoots arising from the distal end of the cluster contributed to the previously reported spread in harvest maturity in 'Showtime Diva' when grown in the field (Samarakoon et al., 2013). The position of buds in a cluster therefore has a significant impact on the spread in harvest maturity, even in the absence of endodormancy.

Commercial implications. From a horticultural perspective, adequate chilling is important for both optimizing floral productivity (Fig. 1A) and for narrowing the spread of harvest maturity (Fig. 2A). In warm temperate climates, crown buds could potentially emerge following the plants receiving only partial chilling, which is likely to result in suboptimal yields and a wide spread in flower harvest.

Application of $\mathrm{GA}_{3}$ before shoot emergence could substitute for chilling except for the additional benefit of extended periods of chilling on shoot length (Fig.1). Unlike chilling, however, $\mathrm{GA}_{3}$ improved production of floral shoots (Figs. 3A and 4A) and shoot length (Fig. 4B), if applied after shoot emergence. Commercial growers may need to determine whether the benefits of application of $\mathrm{GA}_{3}$ outweigh any potential reduction in floral shoot quality. However, the application of both chilling and $\mathrm{GA}_{3}$ appear to be beneficial for both quality and quantity of floral shoots (Figs. 3B and 4B).

In contrast to chilling, the $80 \%$ spread could be narrowed by application of $\mathrm{GA}_{3}$ at any stage of development (Fig. 2), even halving the spread when applied to plants with shoots starting to emerge. Application of $\mathrm{GA}_{3}$ is, therefore, not only capable of substituting for chilling in attaining a greater number of floral stems and reduced duration to harvest maturity, but could be applied so as to narrow the $80 \%$ spread in time to harvest maturity.

For 'Showtime Diva', there was a contribution to the spread ( $10 \mathrm{~d})$ from crown buds located at the distal end of the cluster (Fig. 5). However, since chilling or $\mathrm{GA}_{3}$ was capable of narrowing the spread in time to harvest maturity (Fig. 2A and 5), the contribution to spread from the hierarchical position of a bud can be considered to be less significant than that resulting from inadequate chilling.

While chilling improved floral productivity and timing when applied before shoot emergence, in commercial reality, however, effective chilling temperatures of $5{ }^{\circ} \mathrm{C}$ may be received at any time before and/or after shoot emergence. Subjecting the plants to long-term cold exposure once shoot emergence had commenced reduced floral shoot production quantitatively (Figs. 3A and 4A), and also resulted in plant death $(75 \%)$. At the developmental stage when plants had shoots that were recently emerged, cold exposure was more detrimental to plant survival than at the other stages examined. As this scenario could occur in spring, plant death observed in commercial plantings (Samarakoon et al., 2015) could be partly due to low temperatures after shoot emergence has commenced. In fact, having a mild facultative requirement in a cultivar like Showtime Diva, could be a disadvantage under such circumstances, because crown buds can emerge earlier in the spring (Samarakoon et al., 2013), when the likelihood of periods of damaging cold temperature remains high.

\section{Conclusions}

The developmental potential of a crown bud in gentians is determined by its hierarchical position within the cluster, and the stage in the growth cycle. Crown buds develop endodormancy with a facultative requirement of chilling for shoot emergence. Exposure to cold before shoot emergence therefore improved production of floral shoots qualitatively and quantitatively. $\mathrm{GA}_{3}$ could substitute for chilling before emergence, with the same quantitative effects. Following emergence, when paradormancy predominates, $\mathrm{GA}_{3}$ improved flower productivity qualitatively and quantitatively, in contrast to chilling, which could cause plant death. Inadequate chilling before emergence could lead to a wider spread in timing of flower harvest. $\mathrm{GA}_{3}$ could be applied for a narrower spread in flower harvest maturity at any developmental stage. The current study therefore enabled identification of how crown bud ontogeny and dormancybreaking treatments influence production of floral shoots and the timing of harvest maturity. From a horticultural perspective, the information presented provides potential tools to improve the production of floral shoots in gentians, and to decide what climatic zones might best suit cultivars like Showtime Diva.

\section{Literature Cited}

Chao, W.S., M.E. Foley, D.P. Horvath, and J.V Anderson. 2007. Signals regulating dormancy in vegetative buds. Intl. J. Plant Dev. Biol. $1: 49-56$.

Christiaens, A., E. Dhooghe, D. Pinxteren, and M. Van Labeke. 2012. Flower development and effects of a cold treatment and a supplemental gibberellic acid application on flowering of Helleborus niger and Helleborus $\times$ ericsmithii. Sci. Hort. 136:145-151

Dahanayake, S. and N. Galwey. 1999. Effects of interactions between low-temperature treatments, gibberellin $\left(\mathrm{GA}_{3}\right)$ and photoperiod on flowering and stem height of spring rape (Brassica napus var. annua). Ann. Bot. (Lond.) 84:321-327. 
Eason, J.R., E.R. Morgan, A.C. Mullan, and G.K. Burge. 2004. Display life of Gentiana flowers is cultivar specific and influenced by sucrose, gibberellin, fluoride, and postharvest storage. N. Z. J. Crop Hort. Sci. 32:217-226.

Iversen, R. and T. Weiler. 1994. Strategies to force flowering of six herbaceous garden perennials. HortTechnology 4:62-65.

Lang, G.A., J.D. Early, G.C. Martin, and R.L. Darnell. 1987. Endo-, para-, and ecodormancy: Physiological terminology and classification for dormancy research. HortScience 22:371377.

Marcelis-Van Acker, C. 1994. Development and growth potential of axillary buds in roses as affected by bud age. Ann. Bot. (Lond.) 74:437443.

Ogasawara, N., T. Hiramasu, K. Ishiyama, H. Fushimi, H. Suzuki, and H. Takagi. 2001 Effects of gibberellic acid and temperature on growth and root carbohydrates of Delphinium seedlings. Plant Growth Regulat. 33:181-187.

Ohkawa, K. 1983. Gentiana, p. 351-355. In: A.H. Halevy (ed.). CRC hand book of flowering. CRC Press, Boca Raton, FL.

Samarakoon, U.C. 2012. The physiology and control of crown bud formation and development in gentians. Massey University, Palmerston North, New Zealand, PhD Diss. 4 Mar. 2016. <http://mro.massey.ac.nz/handle/10179/ $4048>$.

Samarakoon, U.C., K.A. Funnell, D.J. Woolley, B.A. Ambrose, and E.R. Morgan. 2014. The architectural complexity of crown bud clusters in gentian (gentianaceae): Anatomy, ontogeny and origin. J. Amer. Soc. Hort. Sci. 139:13-21.

Samarakoon, U.C., K.A. Funnell, D.J. Woolley, G.K. Burge, and E.R. Morgan. 2010. Crown buds in gentians: Appearance, shoot emergence and development. Acta Hort. 937:483-490.
Samarakoon, U.C., K.A. Funnell, D.J. Woolley, and E.R. Morgan. 2012. Temperature impacts changes in crown buds and flowering of gentian 'Spotlight'. Sci. Hort. 143:49-55.

Samarakoon, U.C., K.A. Funnell, D.J. Woolley, and E.R. Morgan. 2013. Evaluation of variation in time of harvest maturity of flowering shoots in three cultivars of gentian. HortTechnology 23:595-601.

Samarakoon, U.C., K.A. Funnell, D.J. Woolley, and E.R. Morgan. 2015. Influence of photoperiod regime and exogenous plant growth regulators on crown bud formation in gentian. Sci. Hort. 182:56-64.

Wanjao, L. and K. Waithaka. 1983. The effect of $\mathrm{GA}_{3}$ application on growth and flowering of liatris. Sci. Hort. 19:343-348.

Zieslin, N. and Z. Geller. 1983. Studies with Liatris spicata Willd. 1. Effect of temperature on sprouting, flowering and gibberellin content. Ann. Bot. (Lond.) 52:849-853. 